\title{
The governance of adaptation: choices, reasons, and effects. Introduction to the Special Feature
}

\author{
$\underline{\text { Dave Huitema }}^{1,2}$, William Neil Adger $^{3}, \underline{\text { Frans Berkhout }}^{4}$, Eric Massev $^{5}$, Daniel Mazmanian $^{6}, \underline{\text { Stefania Munaretto }}^{7}, \underline{\text { Rvan Plummer }}^{8,9}$ \\ and Catrien C. J. A. M. Termeer ${ }^{10}$
}

\begin{abstract}
The governance of climate adaptation involves the collective efforts of multiple societal actors to address problems, or to reap the benefits, associated with impacts of climate change. Governing involves the creation of institutions, rules and organizations, and the selection of normative principles to guide problem solution and institution building. We argue that actors involved in governing climate change adaptation, as climate change governance regimes evolve, inevitably must engage in making choices, for instance on problem definitions, jurisdictional levels, on modes of governance and policy instruments, and on the timing of interventions. Yet little is known about how and why these choices are made in practice, and how such choices affect the outcomes of our efforts to govern adaptation. In this introduction we review the current state of evidence and the specific contribution of the articles published in this Special Feature, which are aimed at bringing greater clarity in these matters, and thereby informing both governance theory and practice. Collectively, the contributing papers suggest that the way issues are defined has important consequences for the support for governance interventions, and their effectiveness. The articles suggest that currently the emphasis in adaptation governance is on the local and regional levels, while underscoring the benefits of interventions and governance at higher jurisdictional levels in terms of visioning and scaling-up effective approaches. The articles suggest that there is a central role of government agencies in leading governance interventions to address spillover effects, to provide public goods, and to promote the long-term perspectives for planning. They highlight the issue of justice in the governance of adaptation showing how governance measures have wide distributional consequences, including the potential to amplify existing inequalities, access to resources, or generating new injustices through distribution of risks. For several of these findings, future research directions are suggested.
\end{abstract}

Key Words: adaptation; climate change; governance

\section{INTRODUCTION}

This introductory article to the Special Feature "The Governance of Adaptation" examines how climate change adaptation is being tackled and organized in society, and how it could and should be governed through individual and collective responses at various scales. Human-induced climate change presents significant challenges to scientific research. It also presents challenges to the media, NGOs, civil society, and, not insignificantly, to politicians and policy makers charged with the task of creating innovative ways to avoid serious risks for many groups, sectors, and regions. Climate change can be seen as a classic problem in public policy given the levels of uncertainty, complexity, and ambiguity. Climate change is not the same problem everywhere; affected social-ecological systems behave in nonlinear ways; costs and benefits of climate change impacts are unevenly distributed; measures to address climate risks can have unexpected and undesired effects; and what is problematic for some might represent an opportunity for others. Hence climate change risks and public and private responses to them are unstructured in the sense that relevant norms, processes, and facts are contested. The research literature on climate change separates mitigation and adaptation with mitigation focusing on reducing perturbations to the carbon cycle as the main cause of human-induced climate change, and adaptation focusing on adjustments to the consequences of climate change in its impacts on natural and social systems. Nevertheless, there has been a realization for more than two decades that adaptation to the impacts of climate change is both necessary and inevitable, and that acting on climate change impacts does not diminish the case for continued and urgent mitigation (Pielke et al. 2007).

Adaptation requires positive adjustment and action, and coordination between actors, even if adaptation is also reactive to changing climate variability. Although much adaptation is likely to be very local and by private parties, coordination among households, organizations, and regions will also be need to achieve key collective objectives, such as flood protection, through adaptation. This means that adaptation requires governance. The term governance "... covers the whole range of institutions and relationships involved in the process of governing" (Pierre and Peters 2000:1). We adopt Kooiman's (1993:4) idea that “... governing refers to the totality of interactions, in which public as well as private actors participate, aimed at solving societal problems or creating societal opportunities; attending to the institutions as contexts for these governing actions; and establishing a normative foundation for all those activities." Governing is seen as directed behavior, involving government and nongovernment parties, aimed at (re)solving a problem, or at reaping the opportunities that a problem presents. Governance requires the creation of institutions, a term that refers to the foundation of new rules, organizations, and policies that give stability to these directed behaviors. The term governance describes "... the patterns that emerge from the governing activities of social, political and administrative actors" (Kooiman 1993:2). It concerns “ "... the ways and means in which the divergent

${ }^{1}$ VU University Amsterdam, the Netherlands, ${ }^{2}$ Open University of the Netherlands, ${ }^{3}$ University of Exeter, ${ }^{4}$ Department of Geography, King's College London, UK, ${ }^{5} \mathrm{VU}$ University, ${ }^{6}$ University of Southern California, ${ }^{7}$ Institute for Environmental Studies (IVM), VU University Amsterdam, ${ }^{8}$ Environmental Sustainability Research Centre, Brock University, Canada, ${ }^{9}$ Stockholm Resilience Centre, Stockholm University, Sweden,

${ }^{10}$ Wageningen University 
preferences of citizens are translated into effective policy choices, about how the plurality of societal interests are transformed into unitary action and the compliance of social actors is achieved" (Kohler-Koch 1999:14).

Adaptation governance refers to the patterns that emerge from the governing activities of social, political, and administrative actors in the realm of climate change adaptation. The governing activities refer to their combined efforts to adapt to climate change, their efforts to found institutions that deal with the issues, and finally they refer to their ideas about appropriate normative underpinnings for the way climate change adaptation should be governed, taking into account wider social and political beliefs and systems. The governance of societal adaptation to climate change has been the subject of research over the past decade, but this continues to be fragmented and has generally failed to inform public policy and private responses.

\section{EMERGING THEMES IN THE DEBATE}

Although adaptation governance is not as firmly entrenched a field of governing when compared to the discussions on mitigation (compare Massey and Huitema 2013), a number of interesting points stand out from our reading of the literature. Below we elucidate these.

First, adaptation is generally associated with different jurisdictional levels than mitigation. Put most simply, mitigation addresses a global problem and is seen as requiring an international and national approach, whereas adaptation is usually described as something that needs to occur at the local or regional level, perhaps with some facilitation or assistance from higher levels (Neufeldt et al. 2010). This is not only to do with specific local climates and variability, but also with varying local vulnerabilities and adaptive capacities.

Second, whereas the leading concepts in mitigation are specific and often quantifiable, e.g., the reduction of $\mathrm{CO}_{2}$ emissions, in adaptation they are either generic (for instance, "to enhance adaptive capacity," "to increase resilience") or very domainspecific (for instance, "to maintain a flood protection standard" or "to protect the productivity of a farming system"). Related to this, one could argue that climate change adaptation governance lacks a commonly agreed core goal or mission. Instead, it is about the protection of many diverse social goals, including the health of vulnerable groups, the resilience of critical infrastructures, the preservation of farming livelihoods, and so on. Thus, it is essentially about "everything," which may lead to the risk of creating confusion and misunderstandings. To paraphrase Wildavsky (1973), if climate adaptation governance is everything, then maybe it is nothing?

Third, it is increasingly understood that adaptation as practiced involves both societal responses to extreme events, as well as forward-looking planning for change and transformation (see Adger et al. 2009). Terms such as adaptability, transformation, adaptive management, resilience, and adaptive governance refer to this forward looking process. Forward projections of climate risks in different places and affecting different groups, and assessments of adaptation options and strategies are knowledgeintensive and often uncertain and contested. This means that conflicts over the scientific underpinning of strategies and policies are also relevant for the governance of adaptation (see van Aalst et al. 2008).
Fourth, there is be a qualitative difference between the thinking about mitigation and adaptation in the sense that mitigation action is constituted mainly by government measures and concentrates on the distinction between regulation on the one hand, and market-based and information approaches (such as labelling, emissions trading, carbon taxation) on the other. The debate on adaptation by contrast has been marked by an emphasis on self-organization and adaptation by social actors, e.g., households, companies, civil society organizations. Adaptation through conventional governance modes of regulation and incentives (e.g., Mees 2014) to overcome deficits and spillovers of autonomous adaptation and self-governance by social sectors are much less common. Self-governance requires innovative capacities and private resources, and these are not spread evenly across society. So apart from the fact that impacts might differ, per region, per city, per neighborhood, and even per household, the capacity to understand and sense new climate-related risks and to respond to them also varies. Coordinated adaptation is also more likely to incorporate issues of fairness in process and to promote the interests and voice of vulnerable populations and more just outcomes.

Fifth, there is an increasing interest in ecosystems-based adaptation, an approach that moves away from a focus on infrastructure toward protecting natural processes and reinstating ecosystems to provide buffering and protection, including water and coastal processes (see, e.g., Vignola et al. 2009, Meijerink and Huitema 2010). Examples include efforts to imitate or recreate new natural reefs in coastal defense works to break the power of high energy tidal waves to replace dykes and dams, and the installation of green roofs as a substitute for air conditioning. Such a shift requires coordination and collective decision making to widen the scope of framing problems and potential solutions.

\section{GOVERNANCE CHOICES}

Having described ongoing discussions in the debate on adaptation governance, we now turn to the question of the design of governance systems or as we deem them here, governance choices. By positing these as choices, we are seeking to bring some further clarity to the discussion, rather than implying that such choices are always explicitly made by governors and other actors in the process of addressing climate change adaptation problems. Frequently, such choices will be the emergent outcomes of complex political and institutional processes. We argue that such choices can vary in a number of respects. Below we detail these (following Jordan et al. 2010) and how they could relate to climate change adaptation (following Massey et al. 2015).

\section{Problem choices}

Governing is a purposive activity, but precisely which problems does it seek to address? Jordan et al. (2010) highlight how actors often engage in struggles to present, or frame, particular phenomena into problems that suit their pre-existing political interests or policy competences. One of the most difficult choices confronting governors relates to which problems to address among all those that concern the public (Dror 1971), how to define, and ultimately how they should be governed. Decision makers often find themselves drawn to particular problems and problem framings because they appear to fit with the way in which they are confronting other problems. This raises new issues. For example, who is deemed responsible for the emergence of this 
particular problem? Have they deliberately caused it or was it an unforeseen outcome of their otherwise legitimate activities?

Massey et al. (2015) suggest that for adaptation to climate change, governments have had a range of options for how to frame and define the adaptation problem. Adaptation has variously been framed as a problem of minimizing risks and sensitivity of people and nature to expected climate impacts, or as a problem of developing the capacity to cope with just extreme weather events, or conversely a problem of developing ways to take advantage of new climatic conditions. Even working within these frames, the choice could be made to define adaptation as a matter of private goods or as collective goods. It might also be framed in terms of competitiveness between governments, where early adapters are able to gain some form of economic advantage over late adapters (see Massey et al. 2014). Last, it might be characterized as an issue of equity and justice, either within countries where disadvantaged groups may be particularly vulnerable, or between the groups of countries, whereby wealthy countries invest in the protection and economic development of less-wealthy countries. In our call for contributions for this Special Feature we welcomed conceptual articles about the way climate change adaptation issues are framed, and empirical analyses of the way in which governors and societal actors perceive and frame adaptation.

\section{Level choice}

Jordan et al. (2010) suggest that after having worked out how to frame a problem, governors have to decide at which level to act. They indicate the main choice is often presented as being between acting locally, that is, decentralization guided by the principle of subsidiarity, or at more aggregated levels, regionally, nationally, or internationally. Massey et al. (2015) imply that although every policy will in one form or another manifest itself at the lowest possible level, perhaps affecting individual citizens, the level at which the policy is designed and implemented will have an impact on its possible effectiveness and distributional impact. They suggest that the development of adaptation policies be carried out across multiple levels and that adaptation is already embedded at the international level within the UN Framework Convention on Climate Change (UNFCCC) and the European Commission (Massey et al. 2015). The choices left for nation-states, according to Massey et al. (2015), are about deciding what roles national, regional, and local governments can play; the degree of their involvement; and the interactions between them. Consequently, relevant questions are about whether there is a need for national level policy framework, or whether government should act in a more advisory, support role to the lower levels? Does primary responsibility for design and implementation reside with municipalities or the regions in which they are located? Here the special issue contributions that address conceptual questions about the politics of scale in adaptation governance, but also contributions discussing adaptation as a problem of multilevel governance were invited.

\section{Timing choices}

Assuming that governors know what problem they want to tackle and at what level, they still need to decide when and in what sequence to act. Jordan et al. (2010) state that identifying an optimal intervention sequence is fraught with difficulty, particularly in a multidimensional domain such as adaptation to climate change that may affect many quite distinct sectors of society and nature. Timing and sequencing dilemmas revolve around issues such as risk taking (moving first without knowing what others may do can be hazardous), profit making (where first movers may reap a potential economic advantage if their approach is eventually "scaled up" to the national or even the global level), and legitimacy (requesting some to act first or bear more of the costs may be viewed as illegitimate). An important choice therefore, is whether to act in a more precautionary manner, or wait for others who do not share the same problem framing and/or want more time to consider the scientific evidence before acting (Jordan et al. 2010). Massey et al. (2015) suggest that uncertainties over the magnitude, type, timing, and location of climate impacts compound the difficulties of making choices in this domain. They suggest that in some cases, though impacts are expected from climate change, for example to levels and intensity of precipitation, even the sign of change (whether an increase or decrease will occur) remains unclear for some regions. Should policy makers take a "wait and see" approach, waiting for better scientific assessments; for impacts to become manifest; for other countries to take a lead they can follow? Additionally, should countries invest in long-term structural measures whose usefulness may only become apparent in 20,50 , or 100 years, or focus on short-term more immediate issues, at the risk of locking into investments that may prove mal-adaptive? Can solutions be developed that are flexible enough to respond to evidence as it improves? Are there priority sectors that require immediate attention? These are the key questions on timing that the special issue invited scholars to address.

\section{Choices concerning modes of governance and instruments}

Which modes of governance will governors select to address problems? Jordan et al. (2010) indicate that the main choice here is between creating and imposing a set of enforceable social norms hierarchically, i.e., through the instrument of regulation, allowing them to emerge and disseminate via market-based instruments in markets, or relying on flatter and more network-based modes in which trust-based incentives play a more important role. Also, they suggest the issue of meta-governance, how to connect the various modes of governance, is relevant (Jordan et al. 2010). Massey et al. (2015) also ask whether adaptation is to be engaged in a regulatory hierarchical manner, or a bottom-up, networked fashion. They also suggest that given the range in which the problem of adaptation could be framed, anyone might be appropriate. Further, given the fact that adaptation is often framed as a multisector problem, the concept has arisen that adaptation should be "mainstreamed" or integrated into the policies and programs of other existing sectors (Massey et al. 2015). Under this heading we invited contributions to this Special Feature that conceptualize the challenge that adaptation presents and connect it to appropriate modes of governance. Empirical analyses that focus on the effectiveness of certain modes of governance, and the conditions under which they work, were also welcomed.

\section{Norms and principles choice}

The governance of adaptation requires monitoring, planning, regulation, decision making, and distributive systems, dispute resolution, and juridical review. All of those are founded nominally in the public interest, but this concept is not unproblematic (for a review see, for instance, McHarg 1999). Principles and norms offer legitimacy for government to take 
measures, provide compensation, use regulatory or economic instruments, and protect rights. Societal consensus on the public interest is based on approved laws, rules, and plans and is nowadays often combined with a deontic (a rule and norm-based) concept in which plans, decisions, etc. are judged by their ethical content and a rights-based approach. This approach has both substantive (human dignity, equal treatment, and property rights) and procedural (fairness or due process, sound administration and transparency, public participation, constraining free-riding, and regulating compliance) aspects. At the same time, there is a revival of elements of both a utilitarianism approach, such as aggregating individual preferences and the use of a cost-benefit analysis, as well as a dialogical approach in which the public interest is a result of a deliberative process among concerned stakeholders and affected parties (McHarg 1999).

These principles affect the kinds of costs and benefits to take into account when making decisions, how to allocate them across different social groups, and whether (and if so, how) to compensate any losers. Jordan et al. (2010) discuss the politics associated with distributive, regulatory, and redistributive policies. The first type involves "... the distribution of services and benefits to particular segments of the population" (Anderson 1984:113). Regulatory policies involve “... conflicts between two groups or coalitions of groups, with one side seeking to impose some sort of control on the other side" (Anderson 1984:114). Finally, redistributive policies involve "... the deliberate efforts by government to shift the allocation of wealth, income, property, or rights among broad classes or groups of the population" (Anderson 1984:115). Jordan et al. (2010) suggest that because these three types of policy allocate costs and benefits differently. They tend to be the outcome of different kinds of politics and hence patterns of governing; in essence, distributive policies are often welcomed by "target groups," whereas redistributive and regulatory policies are more likely to be opposed and lead to conflict. Massey et al. (2015) suggest that deciding how much to spend on adaptation is a daunting challenge. Cost estimates are surrounded by a certain level of uncertainty, and given the expected variability of impacts and their distributional unevenness, the acceptability of spending on adaptation might be different per region. Conceptual articles that discussed normative frameworks that underpin the governance of adaptation, and contributions that empirically probe the meaning and effects of such principles were welcomed in the invitation for the Special Feature.

\section{Implementation and enforcement choices}

Jordan et al. (2010) suggest that the final choice governors must make is how to secure policy results via implementation and how to enforce compliance. Should adaptation be implemented in the classical environmental policy format of top-down steering with one central authority, or can there be multiple centers of authority to decide how best adaptation action could be taken at various levels? Should governments follow a deterrence or compliance approach to ensure that policy goals are met? What sanctions, if any, should there be for noncompliance? Moving beyond these standard distinctions, another choice presents itself for adaptation in particular. Should adaptation actions be mainstreamed into existing policies across sectors or can it be implemented through stand-alone policies? Some policy analysts argue for a top-down approach to studying the implementation and enforcement choices arising when governance is multileveled, whereas others adopt a more bottom-up one (Hill and Hupe 2002). This distinction is useful, because it helps to establish empirically who are the most significant governors and how they affect, or in the future could affect, social change. However, the approaches are based on rather different ontologies. From a topdown perspective, the clarity of goals and the administrative strength of policy instruments are considered to be important requirements. By contrast, the bottom-up approach accepts that goals are ambiguous and implementation "gaps" are the norm rather than the exception. Once again we turned to scholarly contributions in this Special Feature about implementation and enforcement.

\section{APPLYING THE FRAMEWORK TO THE CONTRIBUTIONS}

In the remainder of this article we detail how the contributions of this Special Feature have addressed these governing choices and dilemmas. Table 1 gives an overview of the various contributions. There are 17 contributions, focusing on adaptation governance in nine countries discussing adaptation in a range of fields; notably water management, heat waves, rural development, city government, the built environment, infrastructure, energy, fisheries, and transport. The contributions rely upon different research methods including interviews, focus groups, secondary analysis, and case studies. The Special Feature also includes a range of purely conceptual or normative articles.

The framework outlined above is principally a typology of options for the design of governance systems for adaptation. As such it provides the tools for describing and mapping the choices that decision makers take and thus reveals how a governance system is designed. Such a typology allows for systematic comparison across cases but further analysis is required to determine the motivations behind the choices, and how such choices change over time. Also, the framework does not help predict or explain which effects certain choices might have and why.

Focusing on the reason for choices, for instance, to downplay equity considerations, means treating such choices as a dependent variable. Massey et al. (2014) suggest that major challenges remain. This is because of the current state of the debate on the governance of adaptation, which does not have anything that even closely resembles an agreed conceptual framework on these matters. Given that situation, our ambitions here are largely explorative and we have mined all contributions for indications on why certain governance choices were made. Social science theories illuminate typologies of explanations (following Abma and In 't Veld 2001) distinguishes between (1) institutional explanations, e.g., existing practices in certain jurisdictions create a path dependency and thereby determine governance choices; (2) agency or elitists types of explanations, e.g., the preferences of elected leaders or policy entrepreneurs determine choices; and (3) discursive explanations, the way governors talk and think about climate change issues. They also mention (4) rationalistic explanations, seeking explanations in the context and motivations of governors, including "objective problem pressure"; and finally (5) network-based explanations, e.g., advocacy coalitions. This is not the place to dig deeper in either of these types, but we do want to signal that we shall look for the types of explanations that our authors offer for their findings. 
Table 1. Governance domain and the choice of adaptation focus of contributions to the Special Feature.

\begin{tabular}{|c|c|c|c|}
\hline $\begin{array}{l}\text { Contribution } \\
\text { Jurisdictions }\end{array}$ & Domain & Empirical data & Choices addressed \\
\hline \multicolumn{4}{|l|}{ Baird et al. 2014} \\
\hline Niagara region, Canada & $\begin{array}{l}\text { Water, agriculture, wine } \\
\text { production }\end{array}$ & Interviews (38) with key informants in the region. & $\begin{array}{l}\text { Modes of governance and instruments } \\
\text { choices }\end{array}$ \\
\hline \multicolumn{4}{|l|}{ Bates et al. 2013} \\
\hline Australia & $\begin{array}{l}\text { Forums for government and } \\
\text { business organizations }\end{array}$ & $\begin{array}{l}\text { Interviews ( } 24 \text { ) and focus groups (2) in two study areas, the Swan } \\
\text { Canning region of Western Australia and the Hunter / Central } \\
\text { Coast region of New South Wales. }\end{array}$ & Level choices, timing choices \\
\hline \multicolumn{4}{|l|}{ Benzie 2014} \\
\hline UK & $\begin{array}{l}\text { Coastal communities, heat waves } \\
\text { and droughts, climate change, } \\
\text { justice and vulnerability }\end{array}$ & $\begin{array}{l}\text { Review of studies by the Joseph Rowntree Foundation's Climate } \\
\text { Change and Social Justice program. }\end{array}$ & $\begin{array}{l}\text { Choices related to norms and } \\
\text { principles }\end{array}$ \\
\hline \multicolumn{4}{|l|}{ Dupuis and Knoepfel 2013} \\
\hline Switzerland and India & Rural development policies & $\begin{array}{l}\text { Discourse analysis, how are problem frames translated into policy } \\
\text { documents, and policy outputs }\end{array}$ & $\begin{array}{l}\text { Problem choices, choices regarding } \\
\text { implementation and enforcement }\end{array}$ \\
\hline \multicolumn{4}{|l|}{ Ford et al. 2013} \\
\hline $\begin{array}{l}\text { Not specified, national level } \\
\text { in general }\end{array}$ & Adaptation planning & Not an emphasis but examples used & $\begin{array}{l}\text { Choices regarding implementation and } \\
\text { enforcement }\end{array}$ \\
\hline \multicolumn{4}{|l|}{ Hegger and Dieperink 2014} \\
\hline The Netherlands & Water & $\begin{array}{l}\text { Document analysis, } 30 \text { interviews with researchers, financiers and } \\
\text { policy makers for } 6 \text { different joint knowledge production projects } \\
\text { in The Netherlands }\end{array}$ & Problem choices \\
\hline \multicolumn{4}{|l|}{ Hughes 2013} \\
\hline India (New Delhi) & Adaptation at the city scale & Interviews (21) government, NGO, and academic representatives & $\begin{array}{l}\text { Choices related to norms and } \\
\text { principles }\end{array}$ \\
\hline \multicolumn{4}{|l|}{ Hurlbert and Diaz 2013} \\
\hline Chile and Canada & Water & $\begin{array}{l}\text { Case studies (South Saskatchewan River Basin of western Canada } \\
\text { and the Elqui River Basin in northern Chile), Semistructured } \\
\text { interviews }\end{array}$ & $\begin{array}{l}\text { Modes of governance and instruments } \\
\text { choices }\end{array}$ \\
\hline \multicolumn{4}{|c|}{ Mazmanian et al. 2013} \\
\hline $\begin{array}{l}\text { Not specified, but more } \\
\text { concerned with the U.S. state } \\
\text { level }\end{array}$ & Built environment, infrastructure & Conceptual/normative article & $\begin{array}{l}\text { Timing choices, Modes of governance } \\
\text { and instruments choices, choices } \\
\text { regarding implementation and } \\
\text { enforcement }\end{array}$ \\
\hline \multicolumn{4}{|l|}{ Mees et al. 2014} \\
\hline Local authorities & Adaptation in general & $\begin{array}{l}\text { Normative framework applied to three examples in the city of } \\
\text { Rotterdam }\end{array}$ & $\begin{array}{l}\text { Modes of governance and instruments } \\
\text { choices }\end{array}$ \\
\hline \multicolumn{4}{|l|}{ Munaretto et al. 2014} \\
\hline $\begin{array}{l}\text { Not specific for one } \\
\text { jurisdiction, examples from } \\
\text { all over }\end{array}$ & Adaptation planning & Literature review & $\begin{array}{l}\text { Modes of governance and instruments } \\
\text { choices }\end{array}$ \\
\hline \multicolumn{4}{|l|}{ Plummer 2013} \\
\hline Not specified & Adaptation as a whole & Several examples, but empirics are not the focus here & $\begin{array}{l}\text { Modes of governance and instruments } \\
\text { choices }\end{array}$ \\
\hline \multicolumn{4}{|l|}{ Schneider 2014} \\
\hline Germany & Energy and transport & Secondary analysis of survey data & Modes of governance and instruments \\
\hline \multicolumn{4}{|l|}{ Tomozeiu and Joss 2014} \\
\hline England & Ecotowns/ housing & Document analysis (mainly policy documents) & Level choices \\
\hline \multicolumn{4}{|l|}{ Vasileiadou and Botzen 2014} \\
\hline The Netherlands & Extreme weather & In-depth interviews with 40 persons & Problem choices \\
\hline \multicolumn{4}{|l|}{ Vink et al. 2013} \\
\hline Not specified & Adaptation as a whole & Literature review of some 1200 articles & Timing choices \\
\hline Werners et al. 2015 & & & \\
\hline $\begin{array}{l}\text { Rhine basin, } \\
\text { Italy (Tuscany), } \\
\text { Wadden Sea (Netherlands) }\end{array}$ & $\begin{array}{l}\text { Fisheries, } \\
\text { Wine production, water } \\
\text { management }\end{array}$ & $\begin{array}{l}\text { Reintroduction of the salmon in the Rhine river, changes in } \\
\text { altitude for best wine production, flood safety and nature } \\
\text { protection }\end{array}$ & Timing choices \\
\hline
\end{tabular}


Focusing on the effects of governance choices means treating governance choices as independent variables. There is a plethora of directions in which such effects could be explored. Broadly speaking, governance systems have certain outputs, e.g., the policies they produce, and these in turn have certain outcomes, environmental or societal effects, if you will. Outputs are usually connected to outcomes only after long chains of events, making attribution particularly difficult. Also, the evaluation of both outputs and outcomes can follow a range of logics. Often-used criteria to judge climate governance (see Huitema et al. 2011) are goal related (goal achievement, effectiveness), cost related (costeffectiveness, efficiency), law related (are legal principles followed), process related (fairness, coordination), outcome related (equity, legitimacy), and all can be applied with equal force to climate change adaptation, and if one does one obviously prefers systems that are more efficient, effective, fair, etc. Here too, we simply check the various contributions to this Special Feature, analyzing what is being said in terms of relations between governance choices and patterns in outputs and outcomes; here too we take an explorative approach.

We add a little twist, however, which is that in line with the guiding notions of this journal we pay extra attention to learning and innovation. We propose that systems that are better at learning are more resilient, legitimate, and effective systems. We do not suggest this without some hesitation. This is because we acknowledge the fact that a key function of any governance system (and the institutions embedded therein) is to provide stability and predictability to societal interactions. A governance system that learns and innovates is perhaps always better fitted to its environment and more clearly pursuing its goals, but might also continuously provide changing signals and thus lack such predictability. For instance, we know from Duit and Galaz (2008) that any governance system must strike a balance between "exploration," e.g., seeking new information or seeking new solutions, and "exploitation," e.g., allowing time for existing measures to become effective or to rely on what works. The simple truth is that institutional design choices pose dilemmas between desirable features. However, we believe that in the current situation the bigger risk is that of inaction, of nonlearning, and of not innovating, therefore we place the onus there, and our task becomes uncovering which governance systems perform better in this respect. For us, learning refers to "relatively enduring alterations of thought or behavioral intentions that result from experience" (Sabatier 1998:104) and we hold that three forms of learning are relevant: cognitive learning, normative learning, and relational learning. The first type is to do with the acquisition of new factual information (or better ordering of it), the second with changes in norms, values, and belief systems, and the third with changes in levels of understanding and trust between actors in a governance system (see Huitema et al. 2010). The term innovation can refer to a range of things, but the case has been made that three conceptions of innovations exist side by side (Jordan and Huitema 2014): one emphasizing novel ideas (something is innovative when nobody else has thought of it before), a second emphasizing diffusion (calling something an innovation when it spreads everywhere), and a third focusing on impacts (reserving the term innovative for something that really improves the world). We invoke the term innovation mainly in the second and third meanings, and we insert it here because we cannot simply rely on learning; something needs to actually change and improve and thus innovate.

\section{FINDINGS}

\section{Findings on problems choices}

The articles on problem choices zoom in on problem framing, and teach us three lessons. First is that climate change related issues are being framed in various different ways. Dupuis and Knoepfel (2013) suggest that governors can approach adaptation governance from at least three angles: a climate change-centered angle, a climate variability -oriented angle, and a vulnerabilitycentered angle. In the first approach, linked to the Intergovernmental Panel on Climate Change's (IPCC) fist assessment report (1990), anthropogenic climate change is seen as the problem to be solved. Climate change stimuli are considered to be out of range of natural variability and described as unprecedented. In response, additional, innovative, and often highly technical measures are considered necessary. The climate variability framing is associated with the second IPCC assessment report, and Dupuis and Knoepfel suggest this framing drops the clear distinction between "natural" and "anthropogenic" variability, thereby downplaying the unprecedented nature of the adaptation challenge. Exposure reduction policies are however called for in light of insufficient capacities to address variability, with uncertainty playing a key role in this discourse. The vulnerability-centered angle is associated with the Fourth IPCC assessment report, according to Dupuis and Knoepfel (2013). They suggest that a range of social, environmental, and economic factors limit the current capacity to adapt to external stressors. This discourse proposes a holistic approach in the sense that it focuses on sustainable development and pays extensive attention to the welfare of vulnerable groups, a view echoed by Pelling (2011). In sum, their analysis can largely be seen as an exploration of changes in professional framings around climate change adaptation. Vasileiadou and Botzen (2014), however, suggest that when focusing on extreme weather one should distinguish between framings by experts and those by lay persons. The key difference between these groups is the level of awareness of climate change, which is much higher in the expert community than among lay people.

The second lesson we learn from our contributions is that framings matter. Dupuis and Knoepfel (2013) are particularly interested in consequences for formal (state) policy processes, and specifically the implementation stage in that process. Their argument is that the adoption of a climate centered angle in the problem choice stage leads to higher chances of implementation problems. The other two framings are less demanding because understanding variability in general, and understanding vulnerability is less difficult in terms of scientific literacy. On the basis of this very simple logic, Dupuis and Knoepfel suggest that current eligibility rules for adaptation funding are exerting pressure to implement climate change-centered types of policies because they require project holders to clearly distinguish between baseline development needs and climate change-related actions (Dupuis and Knoepfel 2013). Because of this "interpolicy coordination" conflicts between climate measures and sustainability policies emerge. As such, policy implementation is 
constrained by the uncertainty that characterizes climate impact predictions at the regional level. In the end, they plead for a much stronger focus on the vulnerability centered angle.

The third lesson deals with the possibility of crossing the divide between different problems framings and learning. Vasileiadou and Botzen (2014) suggest that bridging different problem framings is very difficult because expert assessments of climate risks are derived from models, whereas risk assessments by lay people are more determined by direct experience. Secondary information, i.e., hearing about the risks of extreme weather, is far less effective in enhancing awareness. As a compromise solution, they suggest that any communication about the risks of extreme weather events should connect to the personal circumstances and emotions of lay people. Hegger and Dieperink (2014), on the basis of their study of a number of Dutch largescale research efforts in the field of climate change, suggest that joint knowledge production might help create a broad and shared understanding of the problems (collective normative learning), especially when diverse groups of societal actors are involved in knowledge production, and if their reward structures are geared toward coproduction.

In sum, our Special Feature contributions suggest that governors have the choice between a climate, a variability and a vulnerability approach, and that at least the IPCC has shifted its problem framing along these lines over the years, and that certain local governors did the same. Our contributions do not indicate specifically how problem framings shift and whether we should see this as a "natural" progression resulting from increased insight, or whether there is deliberate steering at work. In line with a constructivist perspective, the contributions do clearly indicate that science and policy coconstruct each other (Jasanoff 2004): certain policies require certain scientific disciplines and findings, which in turn suggest certain policy responses. The contributions also indicate that on the policy side implementation of a climatecentered approach (as opposed to a variability or vulnerability one) is more complicated because of the scientific uncertainties about anthropocentric climate change tend to spill over to the problem identification phase of the policy process. The political and power dimensions underpinning problem framing should be a fascinating topic of further analysis. Tentatively we pose that an emphasis on vulnerability (rather than climate change) implies not only that the exact size of climatic changes needs to be known, it also implies a shift in responsibilities, putting the onus on "everyone" to become less vulnerable (and in line with what other scholars suggest as more resilient perhaps?) See, for instance, Tompkins and Adger (2004).

\section{Findings on level choices}

Several of the findings point to the disconnect between climate change science and local and regional governments that are typically tasked with climate change adaptation responsibilities. Mazmanian et al. (2013) join the call for a more scaled down version of climate change projections generated by the IPCC, which would mean that local and regional actors have a more solid basis for developing policy.

In their analysis of the British eco-towns initiative, Tomozeiu and Joss (2014) show how climate change adaptation goals (and even climate policy goals in general) can get lost when such goals are effectively added only later in the policy process; when they are implemented by a bureaucracy with other priorities; and when changes in national politics occur. They call attention to the horizontal and vertical integration that is needed to attain policy goals. And suggest that even if it was a promising development, the eco-town initiative was effectively more focused on affordable housing rather than climate change goals, a consequence of its bureaucratic positioning in the Department of Communities and Local Government, and away from the environmental ministries.

When attempts were made to strengthen the climate change goals of the various local initiatives, it was effectively too late and few initiatives focused substantially on climate change. Finally, when the Labour government lost power, and was replaced by a coalition of Conservatives and Liberals, national policies on this matter were withdrawn, leaving the few eco-towns with an explicit climate agenda to fend for themselves. Although these initiatives may still become successful, Tomozeiu and Joss (2014) ask whether "beyond the immediate challenge of keeping their local initiatives going, these local actors have the capacity to contribute to nationally significant adaptation policy innovation." Here we touch upon a dilemma encountered more often in the literature on "polycentric governance" (see, e.g., Ostrom 2005): given the fact that decentralization means that a certain form of "natural experimentation" enters the governance system, having a decentralized system opens up opportunities for learning and innovation because many units are tinkering with (roughly) similar problems. However, there is a risk, especially when central coordination is missing, that effective strategies cannot be scaled up to other jurisdictions (Ostrom 2005). Bates et al. (2013), in their contribution on adaptation governance in two Australian case study areas, pick up this issue as they suggest that "forums," task forces, advisory committees, conferences, public/private planning processes, and their like, play an important role in the travel of ideas across fragmented governance systems, especially when interactions are repeated and certain actors play a role in multiple forums. In doing so, they enhance social and observational learning, and the actors that link various networks have "capacities [that] represent collective assets that could be utilized in coordinated and well-articulated climate adaptation initiatives" Bates et al. also suggest that the skills of the central players are crucial in learning, but also in managing conflict. They claim that leaders must ensure that " $[\mathrm{t}] \mathrm{he}$ preferences of individuals who do not necessarily agree that climate adaptation responses are essential but who will still be impacted by changes that may occur are accounted for [...] by ensuring that they have equal opportunity to express their opinions in forums and that their concerns are given equal treatment and consideration in discussions and decision making."

Summarizing, our Special Feature contributions (as expected given the dominant discourse on adaptation) really did zoom in on the local and regional levels, with some "forums" carrying responsibility for the connection between various localities and for sharing experiences. The choices that national governments make, however, and the institutional setting in which such national governments embed climate adaptation tasks, e.g., land use planning or environmental policy, does have repercussions for what can and will be done at the local level. The contributions to this Special Feature do make clear that free standing local initiatives might be successful in their own right, but that upscaling successful approaches requires active interaction with other 
localities, either through specially created forums or through the efforts of national governments. If such connections or efforts do not exist, ideas cannot circulate as effectively. Here an interesting research agenda could be forwarded on the theme of governance innovations in polycentric systems: How do such innovations emerge, how do they travel across governance regimes, and which effects do they have?

\section{Findings on timing choices}

The contributions on this theme suggest, on the one hand, the loss of predictability in relation to our climate (Mazmanian et al. 2013 speak of the "the death of stationarity"). Second, they highlight the strong focus of many organizations on the present; Mazmanian et al. (2013) speak of "the dictatorship of the present." Bates et al. (2013) suggest that for business organizations, circumspection is understandable given the level of uncertainty and lack of guidelines for climate change in Australia. They especially suggest that smaller businesses cannot respond because they tend to focus on their core concerns.

Hurlbert and Diaz (2013), on the basis of an analysis of adaptation activities in Chilean and Canadian water management, offer a suggestion as to why governments remain (largely) inactive in the sphere of adaptation policy; they speak of an "adaptation gap." Specifically they point to the "embrace of neo-liberalism as a strategy of development" as a causal factor, meaning states enthusiastically support economic development and pay only cosmetic attention to environmental issues. They state the following:

\section{This strategy is resulting in an increase of risk to many rural agricultural producers and is facilitating adaptation to climate extremes in only a select group of producers. This is very widely known in the Chilean case, where the adoption of neo-liberalism has been especially detrimental in terms of water resources. The adoption of a neo-liberal water code, whereby water is considered a privately owned commodity, has been an imposition of a top-down system that has not only limited the capacity of governance to establish adaptive water strategies at the regional level, but also has imposed a process of competition in a context characterized by an unequal distribution of power [...] resulting in an adaptive capacity to water scarcities that is concentrated in a small number of large producers with the ability to have easier access to water rights.}

In other words, the inactivity of the state mainly affects those who cannot adapt individually.

Werners et al. (2015) concur there is too much inactivity at present, however they propose a way forward. They argue that local or regional climate change assessments are needed and that these should explicitly aim toward defining thresholds, that is explicit statements, embedded in scenario studies, on what is and is not acceptable in terms of climate related risks. The scenario studies should lay the groundwork for future decisions that might become necessary: clarity should be offered in advance on when which decisions need to be taken, stakeholders need to be identified, and policy plans developed. They suggest that adding such a forward oriented component to the current policy cycles, i.e., long-term budgets, land use planning, could go a long way in preparing for an uncertain future.

Vink et al. (2013) also point to the importance of the long term. Through a meta-analysis of the science-policy interface literature in relation to climate change, they find that this literature has (so far) essentially ignored the long-term interplay between "powering" and "puzzling." They suggest that a number of policy cycles will occur before any climate impacts become visible, thus the effects of adaptation can be evaluated. Moreover during that time, institutional learning and negotiations over societal values, interests and goals are bound to occur. This means that in assessing the potential for climate adaptation measures, one should not adopt a static view of power constellations as is currently common practice, but rather a fluid one. In combination with the suggestions by Werners et al. (2015), this presents a slightly more hopeful vision for the future.

Summarizing the contributions on this theme confirm that many organizations and governments take a wait and see approach to climate change adaptation issues. At times, governments, because of ideological reasons, do not see much of a task for themselves. And more generally, it appears that smaller organizations, including businesses, focus on their core tasks. Following Duit and Galaz (2008), such organizations have a weak explorative capacity and do not scan the future for possible surprises. When such surprises do occur, many of these organizations are relatively unprepared. On a more positive note, the "forums" that Bates et al. (2013) analyzed do seem to offer a relatively low-cost option for communicating and learning about climate change. Additionally, there is insight that over the long run power constellations might loosen up and currently unwelcome messages or measures related to climate change might fall on more fertile ground (Vink et al. 2013).

\section{Findings on modes of governance and instruments}

We received quite a few contributions on this topic, ranging from fundamental considerations on collective action dilemmas to very concrete findings on specific instruments. Mazmanian et al. (2013) describe how adaptation is often seen as a responsibility of private actors (so called autonomous adaptation), but, turning the traditional view of adaptation as a private responsibility on its head, suggest that a case for government involvement can be made in quite a few instances, notably (1) when significant spillovers or free-riding occurs from private adaptation actions, meaning that certain actors either suffer from the adaptation actions of others, or that they benefit without contributing; (2) when significant economies of scale or coordination are involved, making a collective approach more efficient; and (3) when significant distributional implications or social justice concerns occur. The consequence is that adaptation, very much like mitigation, is at minimum a shared responsibility between the private and public sectors.

The contribution by Schneider (2014) is of relevance here. In writing about "critical infrastructures" that have been privatized in recent decades (such as power plants) she argues that private sector decisions in the realm of climate adaptation can have collective repercussions. She asks the following: "When former state tasks, especially those involving critical infrastructures, are transferred to private enterprises that postpone essential climate 
change adaptation measures, the question arises as to who bears responsibility for deficits or the failure of critical infrastructure service provision caused by climate change impacts." She suggests a regulatory framework that both accounts for the state's position of ultimate responsibility, which has remained according to most authors in this field, but that at the same time enables flexible, private-sector adaptation to climate change. Her analysis of the way the German state regulates critical infrastructures suggests, however, that this has not yet become a reality because the German public authorities do not "account for the responsibility for climate change adaptation by private-sector critical infrastructure providers in a coordinated and comprehensive manner" (Schneider 2014). It would therefore seem that the responsibility for climate change adaptation falls somewhat between the cracks in the system.

At a slightly lower level of abstraction, several contributions deal with what can be called approaches to governance, such as participatory approach, or (adaptive) comanagement. Hurlbert and Diaz (2013) for instance are very positive about the development of local water advisory committees and their integration into watershed management in both Canada and Chile. They argue that " $[\mathrm{t}]$ hese collaborative arrangements are not only important to secure political agreement around the climate change agenda, but also to establish forms of governance that could channel the participation of civil society in the implementation of collective tasks oriented to secure the resiliency of society" (Hurlbert and Diaz 2013). This Special Feature also contains quite a few ideas on how to concretely shape public participation in such forums. Baird et al. (2014) suggest the production of a "social-ecological inventory" (plotting the state of ecosystems, and societal systems, plus their interactions and dynamics) and Munaretto et al. (2014) pose that participatory multicriteria methods could be of use to concretely shape and steer the debate in such forums.

Few contributions to this Special Feature make an empirical analysis of the effects of such participatory approaches. The exception is Hegger and Dieperink (2014) who actually did not find evidence that involving broad coalitions of actors in the coproduction of knowledge enhanced the salience, credibility, or legitimacy of that knowledge, but neither that such involvement had a detrimental effect.

Plummer (2013) addresses the usefulness of adaptive comanagement in the context of the challenges that climate change adaptation poses. Adaptive comanagement centers on "... collaboration among heterogeneous actors with diverse interests, institutions that are flexible and nested across scales and levels, and analytic deliberation that develops understanding through multiple knowledge systems; builds trust through repeated interactions; and fosters learning and adaptive and continuous feedback through continuous feedback" (Plummer 2013). Connecting to the earlier distinction between public and private provision and benefits in adaptation, they suggest that "[i]t is the domain of private adaptation for public benefit in which adaptive comanagement is best positioned to offer support as it brings together public and private actors to address an environmental or resource problem, typically a common resource, with diffuse benefits not accruing to the individuals." In addition he analyzes the extent to which climate change adaptation issues fit with the conditions for successful adaptive comanagement as outlined by Armitage et al. (2009), which suggest that adaptive comanagement is suitable for well-defined resource system, smallscale resource use contexts, reasonably clear property rights, and national and regional policy environments. On this level Plummer's (2013) conclusion is relatively bleak: "The context of climate change seems to add a level of 'abstraction' and a lack of immediacy, which may precipitate stakeholders to act in other adaptive comanagement situations."

Finally, Mees et al. (2014) in their contribution, offer a practical approach for local government actors that can help them assess ex-ante the various tools at their disposal. This approach offers insights into the general characteristics of various instrument types, information on how these instruments handle specific challenges associated with climate change, and how they fit to certain goals one could want to achieve in certain adaptation contexts. An application of the framework leads, for example, to the conclusion that "performance standards" (regulations by local government) work best in stimulating the construction of green roofs.

Summarizing our findings, we see again traces of neoliberal thinking, in which the state should leave the resolution of societal problems largely to the private sector. The interesting case of critical infrastructure in Germany suggests however that even when the responsibility for these infrastructures have been privatized, there might still be a legacy effect of former stateoriented thinking in the sense that the new private owners of this infrastructure are hesitant to prepare for climate change, seeing that mainly as a task for the government. In connection with this, the contributions presented here have helped us better position certain promising governance approaches such as adaptive comanagement; the suggestion is that it fits well with situations where private adaptations for public benefit are warranted. Public participation is an essential component of adaptive comanagement and it is striking how many authors endorse the need to discuss climate change issues in an open and transparent way. But the puzzle appears to be how to align this recommendation with the abstract character of climate change issues, and the lack of immediacy that Plummer (2013) speaks of.

\section{Findings on choices related to norms and principles}

There were only a few contributions on this topic, primarily focusing on the criterion of justice. These contributions bring important conceptual advances and paint a disturbing picture of how climate change can compound existing inequities in both developed and developing countries. On the conceptual level, Hughes (2013) does a good job of providing a framework for the assessment of procedures and outcomes of adaptation planning, and for understanding the underlying reasons for the attainment of certain levels of justice. She defines justice in urban climate change adaptation as "just adaptation justly achieved." This is elaborated by giving three criteria, (1) inclusiveness, i.e., representation of vulnerable groups in adaptation planning processes for a city; (2) prioritization, i.e., priority setting and framing that recognize the adaptation needs of the vulnerable groups in a city; and (3) impacts, i.e., impacts of adaptation that enhance the freedoms and assets of vulnerable groups in a city. The underlying mechanisms explaining justice outcomes are to be sought in (1) the political economy of poverty, to do with 
political representation and access to decision making; (2) thick injustice, or injustice in the distribution of burdens and benefits, which is rooted in historical processes and is a legacy of past policies that continue to affect the participation opportunities, engagement, and outcomes of decisions surrounding land use planning and public services; (3) technocratic governance, which is the dominance of technical information in policy making that can marginalize groups that are not using, familiar with, or included by this information; and (4) institutional capacities of local government, which means they lack the administrative, financial, or technical capacity to successfully develop and implement new policies and programs (Hughes 2013).

Hughes' study of adaptation planning efforts in Delhi unfortunately paints a bleak picture. Vulnerable groups are not adequately represented in adaptation planning as decisions are taken in a centralized and nontransparent way; vulnerable groups are mentioned in the adaptation plan but their interests are defined in a narrow way and priority is given to the middle-class; finally the assets of vulnerable groups have not increased during the period in which the plan was implemented. The reasons for this high level of injustice are located in two of the four potential factors from the framework: the lack of institutional capacity in the city administration, and the political-economy of poverty. On the lack of institutional capacity Hughes (2013) writes the following:

\begin{abstract}
Funding for climate change adaptation is extremely limited. There are currently no dedicated funding streams for climate change at the city level. Funding from the national level will depend on the extent to which the state action plan aligns with national priorities. Funding through the Clean Development Mechanism (CDM) tends to favor very large projects that may not address the needs of poor and marginalized communities. There is also a lack of technical capacity in the city. All of the assessment components of the state action plan have been contracted to outside entities, including the vulnerability assessment, emissions inventory, and climate projections and scenario development (...). Finally, there is a lack of institutional capacity. There is no dedicated office for climate change in the city and currently very little invested leadership in developing a robust and just state action plan (Hughes 2013).
\end{abstract}

On the political economy of poverty Hughes (2013) says: "The poor and informal populations of the city have very limited venues for accessing decision making, government programs, and public services in Delhi," which is largely to do with the fact that the very vulnerable populations live in unauthorized areas, which formally do not exist.

Benzie's contribution (2014) on flood management in the UK, echoes several of the points made by Hughes. He finds indications that "thick injustice" is occurring in the UK as well. In an effort to highlight the social nature of climate change causes and consequences, he suggests, "it is possible to identify a "quadruple injustice" to climate change within the UK. Certain disadvantaged groups, including those on low incomes, the socially marginalized, and older people: emit the least; may be negatively impacted by mitigation policies; are most vulnerable to climate impacts; and, may be negatively impacted by adaptation policies." In addition, he finds that, at the neighborhood level, there is overlap in vulnerabilities to climate change because $64 \%$ of the extremely socially vulnerable neighborhoods prone to flooding are also classified as extremely vulnerable to heat. Benzie warns against oversimplification though: vulnerable neighborhoods can be very diverse, which means more research at the household level might be needed, and in addition we do not understand the causality behind vulnerability very well. Like Hughes, he does highlight the factor "technocratic governance," however, as he speaks of an "overreliance on top-down assessment techniques [which] may tend to hide the social nature of vulnerability and lead to adaptation strategies that fail to protect the most vulnerable. This would be the consequence of focusing on the size of a risk, or its aggregate costs, rather than on the social nature of the risk: who will suffer harm as a result of that risk" (Benzie 2014). In response, he pleads for "more bottom-up analyses to inform adaptation policy, incorporating procedural elements, such as more consultation with vulnerable groups, as well as methodological elements that base climate risk assessment more on current climate vulnerability and that focus more on identifying cross-cutting issues from different sectors." Summarizing, we can conclude that the concern for justice appears to be lacking in the realm of adaptation governance, and in fact that some of the policies themselves actually widen the gap between social classes.

\section{Findings on choices regarding implementation and enforcement}

Perhaps given that adaptation governance is a field in flux, and it addresses a wide variety of objectives, progress is not so easily monitored. Ford et al. (2013), in their contribution to this Special Feature, capture the complexity well when they list the "three main challenges [that] present obstacles for developing approaches to track adaptation. (1) There is a need to define what adaptation looks like in practice if we are to develop indicators and identify appropriate data sources for monitoring and evaluation. (2) Characteristics of success need to be identified to capture the effectiveness of adaptations in reducing vulnerability. (3) Appropriate data sources need to be identified to facilitate the development and tracking of indicators." They delve into the policy evaluation literature to see which approaches might be suitable for overcoming these barriers. They find that "outcome evaluation," that is, assessing the actual effects of adaptation measures, e.g., in terms of avoided damages, is on the one hand the gold standard in policy evaluation, but on the other hand, practically impossible to apply in the field of adaptation governance. This is because outcome based approaches, "depend on avoided impacts being visible and measurable. Outcome approaches also imply that there is an existing record of impacts over time, with implications for our ability to proactively avert emerging impacts before they occur and, therefore, before they are measured. Attribution is particularly problematic at a national level, with outcomes through which adaptation success can be measured being influenced by many factors besides climate policy and not always being tangible ..." (Ford et al. 2013). They also highlight the challenges posed by the issues of timing and temporality: what might seem to be perfectly effective adaptation measures in the short run may turn out to be very problematic in the long run. Because of this, they look for other forms of adaptation tracking, for instance methods that focus on "adaptation readiness" (e.g., to which extent is political leadership 
Table 2. Domains of design and choice in adaptation governance and their focus, motivation, and potential effects.

\begin{tabular}{|c|c|c|c|}
\hline Governance domain & Principal choice or dilemma & Motivations and justification & Potential effects and outcomes of the domain \\
\hline Problem choices & $\begin{array}{l}\text { Climate, variability- or vulnerability- } \\
\text { centered }\end{array}$ & Scientific advice, framing & Implementation \\
\hline Level choices & Local level, forums for connecting & Institutional factors, forums & Travel of ideas, "upscaling" \\
\hline Timing & Short-term focus, wait and see & $\begin{array}{l}\text { Death of stationarity, uncertainty, } \\
\text { thresholds, neo-liberalism, carelessness }\end{array}$ & $\begin{array}{l}\text { Procrastination, delay, long iteration cycles } \\
\text { between science and policy }\end{array}$ \\
\hline $\begin{array}{l}\text { Modes of governance and } \\
\text { instruments }\end{array}$ & $\begin{array}{l}\text { Private responsibility, unless...., } \\
\text { collaboration and participation, but... }\end{array}$ & $\begin{array}{l}\text { Framing and ideology, spillovers, } \\
\text { economies of scale, distributional } \\
\text { implications }\end{array}$ & $\begin{array}{l}\text { Adaptive capacity, inequity, political agreement } \\
\text { and support }\end{array}$ \\
\hline Norms and principles & Equity considerations ignored & $\begin{array}{l}\text { The political economy of poverty, thick } \\
\text { injustice, technocratic governance, } \\
\text { limitations at the local governance level }\end{array}$ & Accumulation of vulnerabilities and injustices \\
\hline $\begin{array}{l}\text { Implementation and } \\
\text { enforcement }\end{array}$ & $\begin{array}{l}\text { Monitoring and evaluation in their } \\
\text { infancy }\end{array}$ & $\begin{array}{l}\text { Clarity on goals and purposes, clarity } \\
\text { of criteria, missing data, lack of } \\
\text { explicit action theories }\end{array}$ & Progress very hard to monitor \\
\hline
\end{tabular}

present, to which extent is there funding available, to which extent are stakeholders involved), and output-oriented approaches that focus on projects and policies (and assess for instance whether they conform to international best practice). Finally, they suggest that tracking measures of vulnerability might also be an option, the creation of baseline information on vulnerability, or the identification of regions with high levels of vulnerability might help assess the effectiveness of measures in the future.

Mazmanian et al. (2013) suggest, amongst other things, that explicitly identifying the causal logic for policies might help better assess the likelihood of eventual impacts that policies might have (or not). The logic here is that failures in the "action theory" underpinning policy measures will also lead to policy failure. This point connects to the plea that Dupuis and Knoepfel (2013) make for a better integration of the social sciences in the debate on adaptation. They suggest this will help better distinguish between types of adaptation (public or private, purposeful or incidental, and to better conceptualize what is often labeled as "barriers to adaptation." They write "the concept of barriers to adaptation is somewhat under-theorized and has been used phenomenologically to list existing hindrances to public adaptation policy, leaving aside the explanation of their origins or the causal mechanisms by which they operate [...]. It is surprising to note the extent to which knowledge, theories, and conceptual frameworks from sociology and the policy sciences have barely been considered by the research in explaining the political and institutional factors that might hinder the adaptation policy process [...]." In sum, there is a need for clearer definitions of what adaptation governance is exactly about if we are to monitor and evaluate its effects. Furthermore we are stuck mostly with process and output indicators in evaluating such governance, and it would certainly help if governing bodies were more explicit about the assumptions that undergird their actions.

\section{ADAPTATION GOVERNANCE CHOICES: SUMMARY AND A RESEARCH AGENDA}

Following a description of the main findings of each article in the Special Feature, here we draw together the most striking findings and make some suggestions for a research agenda. For our overview, we connect to our descriptive framework, which details the kind of choices governors, in the widest sense, make in the emergence of governance regimes. Table 2 gives an overview of the way these governance choices are made in the countries, regions, and cases discussed in this Special Feature. We remind the reader that this in no way is a representative sample of all efforts at governing adaptation, even if the number of contributions is quite large. We have already indicated that with the term "choice" (or the related term design), we do not refer always to a purposive and organized decision process, but sometimes to a process of emergence of patterns and behaviors. In line with our definitions of governing and governance, many actors will decide to engage or not with climate change impacts and adaptation, and these actors will decide to engage with the governance of new risks and opportunities in particular ways; the pattern that emerges out of this reflects the cumulative effect of all these behaviors, choices, and decisions. Some adaptation governance will emerge from conventional government policy and regulation, democratically legitimated. But much will emerge within and between social groups and organizations more organically. Table 2 also lists the "causes" and "effects" that have been discussed in the previous sections. With both terms we refer to causality; governance choices are made in a certain way; this has certain reasons (causes, underpinning factors) and it has certain consequences (inaction, effects on adaptive capacity, etc.).

Having summarized the governance choices found in the contributions, we now turn toward the most poignant observations about each. In doing so we follow the notion that governance regimes dealing with climate adaptation should be learning oriented.

As for problem choices, the governance of adaptation presents a major dilemma. The key choice appears to be between applying a relatively wide problem frame, which means that governors need to deal with a very wide range of issues (health, water, community development, etc.) but can also use the institutional capacity available for these issues and have the opportunity for more holistic solutions, and a narrow problem frame (only anthropogenic climate change and perhaps focusing on a few key areas). It appears that wider problem frames imply fewer implementation problems later on, and less dependence on uncertain scientific assessments, but at the same time, the experience in land use planning for instance, indicate that some agreement on core objectives, e.g., protecting human life, could provide for a stronger identity. Outside this Special Feature the 
matter has attracted attention too. Bauer and Steurer (2015), for instance, in comparing relatively broad climate action plans in Europe with more targeted versions, suggest that applying a narrower problem definition, e.g., emphasizing water issues, can be quite effective, certainly if this means linking up with a powerful policy sector. The risk is that in such an approach, adaptation measures do not take place in the context of a comprehensive assessment of the risks and opportunities posed by climate change, including trade-offs between sectors, an assessment that is not only desirable but also strongly advocated by the IPCC (Klein et al. 2014). A phased approach, where a broad assessment is followed by a strategy with narrower priorities that can be updated later would then be something to consider. The actual effects, of having a longer term adaptation plan, and having a narrow or broad adaptation strategy should be systematically addressed in comparative research.

In terms of choices about levels of governance, we can point out that largely by default climate adaptation issues are most often placed in the laps of local and regional authorities. However, capabilities at this level are typically limited, certainly when many small organizations are involved. Even if this bottom-up approach does create a quasi-experimental setting, where multiple approaches can be tried out, there is a risk that small initiatives fail to have broader impacts, and that insights gathered on the basis of local quasi-experiments will not reach others who could benefit from these novel approaches. In a truly polycentric governance system as described by Elinor Ostrom (2005), there is a strong central authority present to grow and diffuse novel approaches, but also to produce guides and regulations about proper decision procedures at the local level (transparency, accountability). The contributions about norms and principles suggest that such democratic guarantees are sorely lacking or handed out in a very uneven way. We tentatively suggest then, that more attention should be paid to the need for interaction between local and central governments, and that some central governments should take on a more active role when it comes to climate adaptation. More research on situations wherein central governments are actively involved, versus situations where they stay on the backside, should be pursued.

Regarding timing, we think that the empirically observable trend is to take a wait and see approach, both in government and the private sector. There were hopeful signs, however, about the positive effects of forums where actors could meet and discuss problems and exchange experiences, and about the positive impact of having a long-term approach and vision, which can be linked to every turn of the policy cycle as it occurs. In other words, those propagating climate adaptation policies need to play the long game and be ready for the opportunities that might open up in the future. Explicit attention to adaptation thresholds, that is the advance definition of acceptable and unacceptable climate change effects, appears to be a promising avenue here, but more research on how such thresholds could be defined and the actual impact is warranted.

On modes of governance and instruments, we can conclude that the preferred approach to climate adaptation often consists of private sector responses, but that at the same time there can be quite a few reasons for governments to step in. Mazmanian et al. (2013) identifies three criteria that can help identify situations where the government should step in: when significant spillovers or free-riding occurs from private adaptation actions; when significant economies of scale or coordination are involved, making a collective approach more efficient; when significant distributional implications or social justice concerns occur. There are ample indications that such situations occur quite often: the contributions to this Special Feature are replete with organizations that take a wait and see approach (which means they stand to gain from the innovative activities from others too), and distributional matters and issues of social justice are pretty much absent from the debate (see below). But the devil will be in the detail, for instance, large-scale solutions might be appropriate, i.e. efficient, for issues affecting entire communities at once, but they are also more likely to create certain lock-ins. Such lock-ins could be related to the sunk investments, to the knowledge and organization needed to build such infrastructure, which will want to sustain itself (see for example the case of large scale infrastructure for flood defense in Venice by Munaretto and Huitema 2012), and could also be related to the expectations of the population; in case of large-scale infrastructure they might start assuming that the infrastructure takes care of the issue and they do not need to do anything themselves (see, for example, Engel et al. 2014). In other words, efficiency thinking might lead to greater government involvement, which might subsequently lead to a greater recourse to technical solutions, but whether this is more resilient in the long term is unclear. In such cases, other options are likely to have been closed off at an earlier stage. All this points to the need to study the effects of individual or collective choice processes on the long-term resilience of socialecological systems in more detail.

On norms and principles, we can conclude, surprisingly, that the issue of justice is largely absent from governance debates and planning. The sources of this problem are multiple and not easy to address but it is simply shameful to see that even when governments step in, it is not to address distributional or justice issues associated with climate change. In fact, it is even worse: the articles here suggest that attempts at governing climate change actually add insult to injury by not involving the most vulnerable, by not solving their issues, and thereby potentially increasing differences in society while increasing vulnerability. We join the call of others (see, e.g., Paavola and Adger 2006, Barker et al. 2008, Pelling 2011) for greater insight in methods of concretely remedying this situation. For example, best practices could be studied about methods for effective involvement and empowerment of the most vulnerable groups.

On implementation and enforcement, we can conclude that there is much more to be worked out. Our Special Feature contained valuable contributions that indicate how instruments can be chosen, how progress could be monitored, but much of that still has the feel of a theoretical exercise. Some of the contributions called for better conceptualizations of the "barriers" that might surface in applying these ideas in actual practice and we feel such a call is warranted. Something to address in this realm is the likeliness of a tension between the need for a broad framing of adaptation issues, which apparently helps implementation, and the requirements related to the monitoring of progress. It is currently unclear what adaptation success looks like (Ford et al. 2013) and clarification is likely to be more difficult when adaptation governance aims for multiple goals at once (where 
trade-offs are likely needed). How to effectively strike a balance between such contrasting demands should be studied more intensively.

The final observation points to the interactive effects between the various choices, and to some degree to the dilemmatic character of such choices: from an ideological perspective most governors would prefer an emphasis on private modes of governance, but that may mean that action is postponed or taken in a way that impacts the collective interest. If the government does step in, private parties might become inactive. Participation of the vulnerable is very much needed from an empowerment and justice perspective but their capacities to participate are also the most limited. Broad problem framings might be needed from a political support perspective, but such broad framings make definitive conclusions on progress very hard.

\section{CONCLUSION}

This article has introduced the Special Feature on "The Governance of Adaptation," with the aim of being of interest to all those who are trying to understand this emerging policy field. Our primary argument is that "governors" in the climate adaptation domain need to define the problems they face, choose at what jurisdictional level action will be undertaken, decide when action will be taken, and through which modes of governance and instruments. Furthermore they need to decide which normative principles will be guiding them, and how implementation and enforcement will be arranged. This Special Feature provides a snapshot about the way these choices are currently made globally, why they are made in certain ways, and with which consequences. It suggests that problem definitions can be narrow or broad, and that the way issues are defined has strong consequences for support and effectiveness of governance, and that clear thinking about sequencing may be needed, from broad to narrow and back. In addition, we find that the current emphasis in adaptation governance is very much on the local and regional levels, but that strong arguments are available for a much stronger involvement of higher jurisdictional levels, which are needed for visioning and scaling up of effective approaches. We conclude that climate adaptation governance is a long game, which does not align with shorter political cycles, but which means at the same time that many of such cycles will occur, each offering windows of opportunity for "powering" and "puzzling" (Vink et al. 2013). We have concluded that despite the emphasis on the private sector in the adaptation literature, there can be good reasons for governments to step in, including to manage spillover effects of adaptive action. We believe the climate adaptation community (practitioners and academics alike) needs to start thinking in a more nuanced way about appropriate modes of governance. The current thinking of "barriers to adaptation" has been reviewed in this Special Feature; it is suggested that new conceptualizations are needed. The word barrier might in itself already be misleading because it suggests something fixed, whereas many barriers are an outcome of societal and political processes that are more fluid in the medium and long term. The ignorance of justice in both the practice and study of adaptation governance is one of the most salient points and in greatest need of attention. We find that in some cases, rather than addressing existing injustices, governance measures generate new injustices. Finally, we have discovered that our knowledge on many aspects of the climate adaptation governance problem is still wanting, especially on the underpinning dynamics that explain why certain governance choices are made. Hence we call for targeted research on the dynamics underpinning the development of climate governance regimes, and for research on the effects that some of these choices have.

Responses to this article can be read online at: http://www.ecologyandsociety.org/issues/responses. $\mathrm{php} / 8797$

\section{Acknowledgments:}

The authors wish to acknowledge the support of the Knowledge for Climate Change Programme of the Netherlands' Government.

\section{LITERATURE CITED}

Abma, T., and R. In 't Veld, editors. 2001. Handboek beleidswetenschap. Boom Uitgevers, Amsterdam, The Netherlands.

Adger, W. N., I. Lorenzoni, K. O'Brien, editors. 2009. Adapting to climate change: thresholds, values, governance. Cambridge University Press, Cambridge, UK. http://dx.doi.org/10.1017/ cbo9780511596667

Anderson, J. E. 1984. Public policy making. Third edition. CBS College, New York, New York, USA.

Armitage, D. R., R. Plummer, F. Berkes, R. I. Arthur, A. T. Charles, I. J. Davidson-Hunt, A. P. Diduck, N. C. Doubleday, D. S. Johnson, M. Marschke, P. McConney, E. W. Pinkerton, and E. K. Wollenberg. 2009. Adaptive co-management for socialecological complexity. Frontiers in Ecology and the Environment 7 (2):95-102. http://dx.doi.org/10.1890/070089

Baird, J., R. Plummer, and K. Pickering. 2014. Priming the governance system for climate change adaptation: the application of a social-ecological inventory to engage actors in Niagara, Canada. Ecology and Society 19(1):3. http://dx.doi.org/10.5751/ ES-06152-190103

Barker, T., Ş. Scrieciu, and D. Taylor. 2008. Climate change, social justice and development. Development 51:317-324. http://dx.doi. org/10.1057/dev.2008.33

Bates, L. E., M. Green, R. Leonard, and I. Walker. 2013. The influence of forums and multilevel governance on the climate adaptation practices of Australian organizations. Ecology and Society 18(4):62. http://dx.doi.org/10.5751/ES-06120-180462

Bauer, A., and R. Steurer. 2015. National adaptation strategies, what else? Comparing adaptation mainstreaming in German and Dutch water management. Regional Environmental Change 15 (2):341-352. http://dx.doi.org/10.1007/s10113-014-0655-3

Benzie, M. 2014. Social justice and adaptation in the UK. Ecology and Society 19(1):39. http://dx.doi.org/10.5751/ES-06252-190139

Dror, Y. 1971. Policy sciences: developments and implications. Annals of the New York Academy of Sciences 184:418-431. http:// dx.doi.org/10.1111/j.1749-6632.1971.tb41343.x 
Duit, A., and V. Galaz. 2008. Governance and complexityemerging issues for governance theory. Governance 21:311-335. http://dx.doi.org/10.1111/j.1468-0491.2008.00402.x

Dupuis, J., and P. Knoepfel. 2013. The adaptation policy paradox: the implementation deficit of policies framed as climate change adaptation. Ecology and Society 18(4):31. http://dx.doi. org/10.5751/ES-05965-180431

Engel, K., G. Frerks, L. Velotti, J. Warner, and B. Weijs. 2014. Flood disaster subcultures in The Netherlands: the parishes of Borgharen and Itteren. Natural Hazards 73:859-882. http://dx. doi.org/10.1007/s11069-014-1116-5

Ford, J. D., L. Berrang-Ford, A. Lesnikowski, M. Barrera, and S. J. Heymann. 2013. How to track adaptation to climate change: a typology of approaches for national-level application. Ecology and Society 18(3):40. http://dx.doi.org/10.5751/ES-05732-180340

Hegger, D., and C. Dieperink. 2014. Toward successful joint knowledge production for climate change adaptation: lessons from six regional projects in the Netherlands. Ecology and Society 19(2):34. http://dx.doi.org/10.5751/ES-06453-190234

Hill, M., and P. Hupe. 2002. Implementing public policy. Sage, London, UK.

Hughes, S. 2013. Justice in urban climate change adaptation: criteria and application to Delhi. Ecology and Society 18(4):48. http://dx.doi.org/10.5751/ES-05929-180448

Huitema, D., C. Cornelisse, and B. Ottow. 2010. Is the jury still out? Toward greater insight in policy learning in participatory decision processes - the case of Dutch citizens' juries on water management in the Rhine Basin. Ecology and Society 15(1):16. [online] URL: http://www.ecologyandsociety.org/vol15/iss1/ $\underline{\operatorname{art} 16 /}$

Huitema, D., A. Jordan, E. Massey, T. Rayner, H. van Asselt, C. Haug, R. Hildingsson, S. Monni, J. Stripple. 2011. The evaluation of climate policy: theory and emerging practice in Europe. Policy Sciences 44(2):179-198. http://dx.doi.org/10.1007/s11077-011-9125-7

Hurlbert, M. A., and H. Diaz. 2013. Water governance in Chile and Canada: a comparison of adaptive characteristics. Ecology and Society 18(4):61. http://dx.doi.org/10.5751/ES-06148-180461

Intergovernmental Panel on Climate Change (IPCC). 1990. Climate change: the IPCC scientific assessment. Report prepared for IPCC by Working Group 1. J. T. Houghton, G. J. Jenkins, and J. J. Ephraums, editors. Cambridge University Press, Cambridge, UK.

Jasanoff, S. 2004. States of knowledge: the co-production of science and the social order. Routledge, London, UK. http://dx.doi. org/10.4324/9780203413845

Jordan, A., and D. Huitema. 2014. Policy innovation in a changing climate: sources, patterns and effects. Global Environmental Change 29:387-394. http://dx.doi.org/10.1016/j.gloenvcha.2014.09.005

Jordan, A., D. Huitema, H. van Asselt, T. Rayner, and F. Berkhout, editors. 2010. Climate change policy in the European Union. Confronting the dilemmas of mitigation and adaptation. Cambridge University Press, Cambridge, UK. http://dx.doi. org/10.1017/cbo9781139042772
Klein, R. J. T., G. F. Midgley, B. L. Preston, M. Alam, F. G. H. Berkhout, K. Dow, and M. R. Shaw. 2014. Adaptation opportunities, constraints, and limits. Pages 899-943 in C. B. Field, V. R. Barros, D. J. Dokken, K. J. Mach, M. D. Mastrandrea, T. E. Bilir, M. Chatterjee, K. L. Ebi, Y. O. Estrada, R. C. Genova, B. Girma, E. S. Kissel, A. N. Levy, S. MacCracken, P. R. Mastrandrea, and L. L. White, editors. Climate Change 2014: impacts, adaptation, and vulnerability. Part A: global and sectoral aspects. Contribution of Working Group II to the Fifth Assessment Report of the Intergovernmental Panel on Climate Change. Cambridge University Press, Cambridge, UK.

Kohler-Koch, B. 1999. The evolution and transformation of European governance. Pages 14-35 in B. Kohler-Koch and R. Eising, editors. The transformation of governance in the EU. Routledge, New York, New York, USA.

Kooiman, J. 1993. Governing and governance. Sage, London, UK.

Massey, E., R. Biesbroek, D. Huitema, and A. Jordan. 2014. Climate policy innovation: the adoption and diffusion of adaptation policies across Europe. Global Environmental Change 29:434-443. http://dx.doi.org/10.1016/j.gloenvcha.2014.09.002

Massey, E., and D. Huitema. 2013. The emergence of climate change adaptation as a policy field: the case of England. Regional Environmental Change 13(2):341-352. http://dx.doi.org/10.1007/ s10113-012-0341-2

Massey, E., D. Huitema, H. Garrelts, K. Grecksch, H. Mees, T. Rayner, S. Storbjörk, C. Termeer, and M. Winges. 2015. Handling adaptation policy choices in Sweden, Germany, the UK and the Netherlands. Journal of Water and Climate Change 6(1):9-24. http://dx.doi.org/10.2166/wcc.2014.110

Mazmanian, D. A., J. Jurewitz, and H. T. Nelson. 2013. A governing framework for climate change adaptation in the built environment. Ecology and Society 18(4):56. http://dx.doi. org/10.5751/ES-05976-180456

McHarg, A. 1999. Reconciling human rights and the public interest: conceptual problems and doctrinal uncertainty in the jurisprudence of the European Court of Human Rights. Modern Law Review 62(5):671-696. http://dx.doi.org/10.1111/1468-2230.00231

Mees, H. L. P. 2014. Responsible climate change adaptation exploring, analysing and evaluating public and private responsibilities for urban adaptation to climate change. Dissertation. Utrecht University, Utrecht, The Netherlands.

Mees, H. L. P., J. Dijk, D. van Soest, P. P. J. Driessen, M. H. F. M. W. van Rijswick, and H. Runhaar. 2014. A method for the deliberate and deliberative selection of policy instrument mixes for climate change adaptation. Ecology and Society 19(2):58. http://dx.doi.org/10.5751/ES-06639-190258

Meijerink, S., and D. Huitema. 2010. Policy entrepreneurs and change strategies: lessons from sixteen case studies of water transitions around the globe. Ecology and Society 15(2):21. [online] URL: http://www.ecologyandsociety.org/vol15/iss2/ art21/

Munaretto, S., and D. Huitema. 2012. Adaptive comanagement in the Venice lagoon? An analysis of current water and environmental management practices and prospects for change. 
Ecology and Society 17(2):19. http://dx.doi.org/10.5751/ ES-04772-170219

Munaretto, S., G. Siciliano, and M. E. Turvani. 2014. Integrating adaptive governance and participatory multicriteria methods: a framework for climate adaptation governance. Ecology and Society 19(2):74. http://dx.doi.org/10.5751/ES-06381-190274

Neufeldt, H., E. Jochem, J. Hinkel, D. Huitema, E. Massey, P. Watkiss, and K. Lonsdale. 2010. Climate policy and inter-linkages between adaptation and mitigation. Pages 3-30 in M. Hulme and H. Neufeldt, editors. Making climate change work for us. Cambridge University Press, Cambridge, UK.

Ostrom, E. 2005. Understanding institutional diversity. Princeton University Press, Princeton, New Jersey, USA.

Paavola, J., and W. N. Adger. 2006. Fair adaptation to climate change. Ecological Economics 56(4):594-609. http://dx.doi. org/10.1016/j.ecolecon.2005.03.015

Pelling, M. 2011. Adaptation to climate change: from resilience to transformation. Routledge, New York, New York, USA.

Pielke, R., Jr., G. Prins, S. Rayner, and D. Sarewitz. 2007. Climate change 2007: lifting the taboo on adaptation. Nature 445 (7128):597-598. http://dx.doi.org/10.1038/445597a

Pierre, J., and B. G. Peters. 2000. Governance, politics and the state. Macmillan, London, UK.

Plummer, R. 2013. Can adaptive comanagement help to address the challenges of climate change adaptation? Ecology and Society 18(4):2. http://dx.doi.org/10.5751/ES-05699-180402

Sabatier, P. A. 1998. The advocacy coalition framework: revisions and relevance for Europe. Journal of European Public Policy 5:98-130. http://dx.doi.org/10.1080/13501768880000051

Schneider, T. 2014. Responsibility for private sector adaptation to climate change. Ecology and Society 19(2):8. http://dx.doi. org/10.5751/ES-06282-190208

Tomozeiu, D., and S. Joss. 2014. Adapting adaptation: the English eco-town initiative as governance process. Ecology and Society 19 (2):20. http://dx.doi.org/10.5751/ES-06411-190220

Tompkins, E. L., and W. N. Adger. 2004. Does adaptive management of natural resources enhance resilience to climate change? Ecology and Society 9(2):10. [online] URL: http://www. ecologyandsociety.org/vol9/iss2/art10/

van Aalst, M. K., T. Cannon, and I. Burton. 2008. Community level adaptation to climate change: the potential role of participatory community risk assessment. Global Environmental Change 18:165-179. http://dx.doi.org/10.1016/j.gloenvcha.2007.06.002

Vasileiadou, E., and W. J. W. Botzen. 2014. Communicating adaptation with emotions: the role of intense experiences in raising concern about extreme weather. Ecology and Society 19 (2):36. http://dx.doi.org/10.5751/ES-06474-190236

Vignola, R., B. Locatelli, C. Martinez, and P. Imbach. 2009. Ecosystem-based adaptation to climate change: what role for policy-makers, society and scientists? Mitigation and Adaptation Strategies for Global Change 14:691. http://dx.doi.org/10.1007/ s11027-009-9193-6
Vink, M. J., A. Dewulf, and C. Termeer. 2013. The role of knowledge and power in climate change adaptation governance: a systematic literature review. Ecology and Society 18(4):46. http:// dx.doi.org/10.5751/ES-05897-180446

Werners, S. E., E. van Slobbe, T. Bölscher, A. Oost, S. Pfenninger, G. Trombi, M. Bindi, and M. Moriondo. 2015. Turning points in climate change adaptation. Ecology and Society 20(4):3. http:// dx.doi.org/10.5751/ES-07403-200403

Wildavsky, A. 1973. If planning is everything, maybe it's nothing. Policy Sciences 4(2):127-153. http://dx.doi.org/10.1007/bf01405729 